\title{
Trends of Cardiovascular Mortality in Blacks Africans from Central African City: Hospital Based Study, Brazzaville (Congo)
}

\author{
Bertrand F. Ellenga-Mbolla1,2*, Aude Loko-Lemba'2, Solange F. Mongo-Ngamami1, \\ Christian M. Kouala-Landa², Igor Ondze-Kafata ${ }^{2}$, Stephane M. Ikama ${ }^{2}$, Thierry R. Gombet ${ }^{2}$, \\ Gisèle Kimbally-Kaky',2
}

${ }^{1}$ Department of Cardiology, University Teaching Hospital of Brazzaville, Brazzaville, Congo

${ }^{2}$ Department of Doctoral Studies, Faculty of Health Sciences, Marien Ngouabi University of Brazzaville, Brazzaville, Congo

Email: *ellenga_bertrand@hotmail.com

How to cite this paper: Ellenga-Mbolla, B.F., Loko-Lemba, A., Mongo-Ngamami, S.F., Kouala-Landa, C.M., Ondze-Kafata, I., Ikama, S.M., Gombet, T.R. and Kimbally-Kaky, G. (2019) Trends of Cardiovascular Mortality in Blacks Africans from Central African City: Hospital Based Study, Brazzaville (Congo). World Journal of Cardiovascular Diseases, 9, 698-705. https://doi.org/10.4236/wjcd.2019.99063

Received: August 24, 2019

Accepted: September 22, 2019

Published: September 25, 2019

Copyright $\odot 2019$ by author(s) and Scientific Research Publishing Inc. This work is licensed under the Creative Commons Attribution International License (CC BY 4.0).

http://creativecommons.org/licenses/by/4.0/ Open Access

\begin{abstract}
Background: To determine mortality causes and the associated factors. Patients and Method: This cross-sectional study was conducted from June 2014 to May 2015 (1 year) in the department of cardiology at University and teaching Hospital of Brazzaville. Patients admitted for cardiovascular diseases were included. Patients admitted for cardiovascular disease in other departments of the hospital, or without cardiovascular diseases were not included. Results: In total, 1035 patients, 605 women (5804\%) were included. Mean age was $57.1 \pm 7$ years (range: $18-85$ years). The patients were: elderly ( $\mathrm{n}=498$, $48.1 \%)$, educated ( $n=809,78.1 \%)$, low-income $(n=253,24.2 \%)$. The medical history of patients was: hypertension $(n=440,42.5 \%)$, diabetes $(n=316$, $30.5 \%)$, reduced physical activity $(\mathrm{n}=154,14.9 \%)$, excessive alcohol intake ( $\mathrm{n}$ $=56,5.4 \%)$. Heart failure was reported in 386 cases (37.3\%). The mortality rate was $8 \%(\mathrm{n}=83)$; the mean age of deceased was $61.9 \pm 7.3$ years $(\mathrm{p}<$ $0.0001)$. The associated diseases in death were dilated cardiomyopathy $(\mathrm{n}=$ 37, 44.6\%, OR 5, 95\%CI $3.1-8, \mathrm{p}<0.0001)$, hypertensive heart disease $(\mathrm{n}=$ $30,36.1 \%$, OR $2.1,95 \%$ CI $1.3-3.3, \mathrm{p}=0.002)$, atrial fibrillation $(\mathrm{n}=24,29 \%$, OR 3.6, 95\%CI $2.2-6, \mathrm{p}<0.0001)$, acute stroke $(\mathrm{n}=6,7.2 \%$, OR $3.8,95 \% \mathrm{CI}$ $1.4-9.8, \mathrm{p}=0.005)$. The associated death comorbidities were: acute respiratory infection ( $\mathrm{n}=44,53 \%$, OR 10.1,95\%CI $6.2-16, \mathrm{p}<0.0001)$, anemia $(\mathrm{n}=$ 27, 32.5\%, OR 6, 95\%CI $3.5-10 \mathrm{p}<0.0001)$, kidney failure $(\mathrm{n}=17,20.5 \%$, OR 3.7, 95\%CI $2-6.8, \mathrm{p}<0.0001)$. Conclusion: Hypertension, heart failure and cardiomyopathies are the leading causes of mortality in the department of cardiology. Prevention and patient education in a low-income environment are essential elements to reduce this morbidity.
\end{abstract}




\section{Keywords}

Mortality, Cardiovascular Disease, Blacks Africans, Sub-Saharan Africa

\section{Introduction}

Cardiovascular disease (CVD) has become the leading cause of death worldwide [1] [2]. The majority of these deaths occur in developing countries. Cardiovascular mortality is over 1 million in Africa, accounting for $11.3 \%$ of all causes, and $38 \%$ of noncommunicable diseases in 2013 [2]. In sub-Saharan Africa, the increasing prevalence of cardiovascular risk factors is related to lifestyle changes and the increase of life expectancy [3]. In addition, rheumatic heart disease (RHD) remains a public health problem in these regions of the world where their prevalence is high [4] [5] [6]. The main causes of heart diseases in sub-Saharan Africa are hypertension, cardiomyopathies, RHD and ischemic heart disease [6] [7].

Global initiatives for hypertension screening for an effective control are encouraged, and some initiatives have been undertaken [8] [9], including screening and prevention of RHD [4] [5] [10]. These diseases have various intra-hospital prognosis in Brazzaville due to various mortality causes according to several studies [3] [11].

In Brazzaville, the prevalence of hypertension is $41 \%$ [8]. It is the leading cause of hospitalization in the department of cardiology, and the majority of patients are admitted for heart failure [3] [11].

The aim of this study was to evaluate the mortality causes and their associated factors, in the department of cardiology.

\section{Patients and Method}

Type, period, and setting. This cross-sectional study was conducted from June 2014 to May 2015 (1 year) in the department of cardiology at the University Teaching Hospital of Brazzaville.

Inclusion: Patients admitted for CVD in the cardiology department were included. Patients with CVD, and admitted to other departments of the hospital were not included. Similarly, patients admitted for other disease associated with a non-symptomatic CVD were not included.

Ethics: Confidentiality was assured according to the protocol of Helsinki (1975), and the authorization of the Ethics Committee of the Faculty of Health Sciences (Marien Ngouabi University of Brazzaville) was obtained. The data was collected on a study form.

Items: Variables analyzed were epidemiological, clinical, diagnostic and prognostic.

\section{Definitions:}

- Elderly: patient over 60 years old, according to the occupational retirement 
age in Congo, and the life expectancy (62.3 years) [1] [12].

- Excessive alcohol intake: was defined by the regular consumption of alcohol [8].

- Current smoking: active or passive smoking, or have quit smoking for less than 3 years.

- Reduced physical activity was retained when physical activity in lifestyle was reduced, to less than 150 minutes per week of moderate physical activity, or to less than 75 minutes a week of vigorous aerobic physical activity, according to European Society of Cardiology guidelines [9].

- Low income patient: income under 1.96 US dollar per day according to the World Bank [12].

- High income patient: income above twice the minimum wage in the Republic of Congo evaluated to 150 US dollars per month [12].

- Educated patients: having high school or university education.

- Hypertension: Patient with systolic blood pressure (BP) $\geq 140 \mathrm{mmHg}$ systolic or/and diastolic $\mathrm{BP} \geq 90 \mathrm{mmHg}$, or taking antihypertensive medication.

- Diabetes: fasting glucose $\geq 1.26 \mathrm{~g} / \mathrm{L}$, or taking antidiabetic treatment.

- Kidney failure: estimated glomerular filtration rate $<60 \mathrm{~mL} / \mathrm{min} / 1.73 \mathrm{~m}^{2}$ by the MDRD formula [13].

- Anemia: hemoglobin $<12 \mathrm{~g} / \mathrm{dL}$ in men, and $<13 \mathrm{~g} / \mathrm{dL}$ in women, or less than 2 units of usual value [14].

- Pulmonary Hypertension: retained when systolic pulmonary pressure obtained by cardiac ultrasound is $>35 \mathrm{~mm} \mathrm{Hg}$.

Statistical analysis. the data were entered in Excel Microsoft $\odot$ and analyzed by the software Epi Info3.3.2@ (CDC Atlanta, USA). Qualitative variables were presented in number ( $\mathrm{n}$ ) and percentage (\%). Quantitative variables were presented on mean \pm standard deviation and range. The comparison of qualitative variables used the Chi-squared test. For the comparison of quantitative variables, the Student's t-test was used. An Odds-ratio (OR) calculation was performed with their $95 \%$ confidence interval (CI) to determine the associated factors of mortality. The significance threshold for comparisons was $<5 \%$.

\section{Results}

A total of 1035 patients were admitted, including 605 women (58.4\%). The mean age was $57.1 \pm 7$ years (range: $18-85$ years), age $<40$ years $(\mathrm{n}=186,18 \%)$, and $>60$ years $(n=498,48.1 \%)$. The socio-demographic characteristics and medical history of patients are presented in Table 1 . Heart failure was reported in 386 cases $(37.3 \%)$. Acute respiratory distress $(\mathrm{n}=181,17.5 \%)$ and shock $(\mathrm{n}=$ $25,2.4 \%)$ were recorded.

The mortality rate was $8 \%(n=83)$. The mean age of the deceased patients was $61.9 \pm 7.3$ years $(\mathrm{p}<0.0001)$. Figure 1 shows the mortality rate by age group. The mortality for HF was $16.3 \%(\mathrm{n}=63, \mathrm{p}<0.0001), 88 \%$ for acute respiratory distress $(\mathrm{n}=79, \mathrm{p}<0.0001)$, and $14.4 \%$ for shock $(\mathrm{n}=12, \mathrm{p}<0.0001)$. 
Table 1. Sociodemographic findings and medical history of patients admitted in department of cardiology.

\begin{tabular}{ccc}
\hline & $\mathrm{n}$ & $\%$ \\
\hline Sociodemographic findings & & \\
Female sex & 605 & 58.4 \\
Educated patients & 809 & 78.1 \\
High-income patient & 519 & 50.1 \\
Low-income patient & 253 & 24.4 \\
Medical history & & \\
Hypertension & 440 & 42.5 \\
Diabetes mellitus & 316 & 30.5 \\
Reduced physical activity & 154 & 14.9 \\
Excessive alcohol intake & 56 & 5.4 \\
Current smoking & 39 & 3.8 \\
Tuberculosis & 52 & 5 \\
HIV under ART & 15 & 1 \\
\hline
\end{tabular}

HIV: human immunodeficiency virus. ART: antiretroviral therapy.

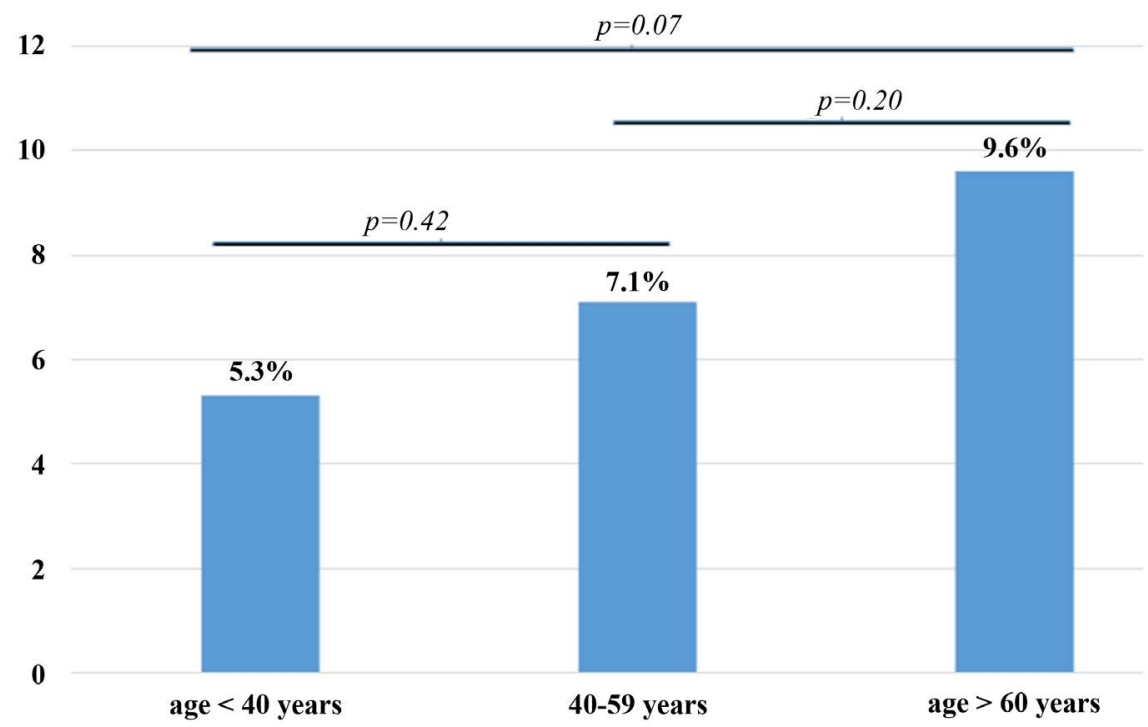

Figure 1. Evolution of mortality rate by age range.

The bivariate analysis of associated factors with mortality is reported in Table 2 . The mean duration of hospitalization was $10.4 \pm 9.4$ days (range: $2-75$ ).

\section{Discussion}

The profile of patients admitted to our department shows that females and elderly patients predominate, as some authors have also described [2] [15]. The feminine gender contrasts with data of high-income countries, where males are more affected. This difference is related to the delay of consultation often attributed to men, and in the high-income countries, ischemic heart disease is involved [2] [3]. Indeed, because of not only prejudices, beliefs, illiteracy and ignorance, patients consult late [3]. This explains the severity of symptoms: respiratory distress, shock and anemia. The most common pathologies are hypertension 
Table 2. Associated factors in death in bivariate analysis.

\begin{tabular}{|c|c|c|c|c|}
\hline & $\begin{array}{l}\text { Death } \\
\mathrm{n}(\%)\end{array}$ & $\begin{array}{c}\text { No death } \\
\mathrm{n}(\%)\end{array}$ & OR (IC95\%) & p-value \\
\hline \multicolumn{5}{|l|}{ Epidemiology } \\
\hline Female sex & $42(50.6)$ & $563(59.1)$ & $0.7(0.4-1.1)$ & 0.13 \\
\hline Low-income patient & $17(20.4)$ & $236(24.8)$ & $0.78(0.4-1.3)$ & 0.38 \\
\hline Elderly & $48(57.8)$ & $498(52.3)$ & $1.2(0.8-2)$ & 0.33 \\
\hline Hypertension & $36(43.3)$ & $404(42.4)$ & $1.03(0.6-1.6)$ & 0.86 \\
\hline Reduced physical activity & $22(26.5)$ & $132(13.8)$ & $2.2(1.3-3.7)$ & 0.002 \\
\hline Excessive alcohol intake & $12(14.5)$ & $44(4.6)$ & $3.4(1.7-6.9)$ & $<0.001$ \\
\hline Diabetes mellitus & $11(13.2)$ & $305(32)$ & $0.32(0.1-0.6)$ & $<0.001$ \\
\hline \multicolumn{5}{|l|}{ Cardiovascular disease } \\
\hline Dilated cardiomyopathy & $37(44.6)$ & $132(13.8)$ & $5(3.1-8)$ & $<0.0001$ \\
\hline Hypertensive heart disease & $30(36.1)$ & $202(21.2)$ & $2.1(1.3-3.3)$ & 0.002 \\
\hline Atrial fibrillation & $24(29)$ & $95(10)$ & $3.6(2.2-6)$ & $<0.0001$ \\
\hline Valvular heart disease & $7(8.4)$ & $48(5)$ & $1.4(0.6-3.5)$ & 0.39 \\
\hline Ischemic heart disease & $6(7.2)$ & $45(4.7)$ & $1.5(0.6-3.7)$ & 0.31 \\
\hline Acute stroke & $6(7.2)$ & $19(2)$ & $3.8(1.4-9.8)$ & 0.005 \\
\hline Pulmonary embolism & $5(6)$ & $38(4)$ & $1.5(0.6-4)$ & 0.37 \\
\hline Pulmonary hypertension & $5(6)$ & $72(7.5)$ & $2.7(0.9-7)$ & 0.05 \\
\hline Tamponnade & $5(6)$ & $12(1.2)$ & $5(1.7-14)$ & 0.003 \\
\hline Complete heart block & $3(3.6)$ & $2(0.2)$ & $17.8(2.9-108)$ & 0.001 \\
\hline \multicolumn{5}{|l|}{ Comorbidities } \\
\hline Acute respiratory infection & $44(53)$ & $95(10)$ & $10.1(6.2-16)$ & $<0.0001$ \\
\hline Anemia & $27(32.5)$ & $72(7.5)$ & $6(3.5-10)$ & $<0.0001$ \\
\hline Kidney failure & $17(20.5)$ & $61(6.4)$ & $3.7(2-6.8)$ & $<0.0001$ \\
\hline Tuberculosis & $7(8.4)$ & $45(4.7)$ & $1.8(0.8-4.2)$ & 0.14 \\
\hline HIV & $5(6)$ & $27(2.8)$ & $2.1(0.8-5.8)$ & 0.11 \\
\hline Cancer & $2(2.4)$ & - & - & - \\
\hline
\end{tabular}

HIV: Human immunodeficiency virus.

(42.5\%) and heart failure (37.3\%). This trend has been found by many African authors [1] [7] [15] [16]. In our study, the mortality rate in the department of cardiology was $8 \%$. This mortality is higher in elderly patients. This fact is comparable to the CVD mortality rate, estimated at $9 \%-13 \%$ in SSA [2].

Dilated cardiomyopathies (DCM) are caused by various diseases in Africa [6] [11]. It is a disease whose incidence is increasing in SSA, estimated at $12 \%$ [1]. The long-term treatment is often limited, and heart failure often becomes refractory, with a fatal outcome [7] [11] [17] [18]. Hypertensive heart disease may eventually lead to DCM [6]. Hypertensive heart disease remains a major challenge in our countries. In fact, although hypertension is detected, its treatment remains insufficient and complications are frequent and early [8] [19]. In Africa, atrial fibrillation is often associated with hypertension, cardiomyopathies and valvular heart disease [1] [16]. Stroke are the leading cause of death in adults at the University and teaching Hospital of Brazzaville, and represent the leading cause of CVD mortality in sub-Saharan Africa [2] [3] [20]. It is a disabling disease whose management has been improved with the setting up of a neurovascular intensive care unit in Brazzaville [20]. Acute stroke events admitted in time, remain inadequately treated due to a lack of fibrinolysis [20]. Patients with 
complete heart blocks often remain untreated for a lack of pacemaker and the risk of sudden death is increased [21]. Missions by humanitarian agencies for the implementation of pacemakers are rare and costly for the government of the Republic of the Congo [21]. Several comorbidities were associated with death. Acute respiratory infections are often severe in high-risk patients, contributing to increased mortality, as in the elderly, but also in patient with heart failure [22]. They are the cause of severe sepsis and shock, and the treatment is difficult [22]. Anemia is often reported in patients with heart failure (15.2\%) in sub-Saharan Africa [7]. Anemia is associated with iron deficiency, requiring long-term treatment and multidisciplinary team supervision [14]. In Africa, in terms of living conditions and the lack of care, the prognosis in this context is poor [14]. Another obvious cause of death is kidney failure. Indeed, kidney failure is often discovered at the terminal stage, the cost of dialysis is expensive, and dialysis centers are not functioning properly in Brazzaville [13].

Of these results, hypertension and its complications (heart failure, stroke, and kidney failure) are a major cause of death. This situation seems to be linked to poor preventive measures [2] [19]. Actions for an early and efficient management of patients seem to be indicated [9]. CVDs are chronic diseases, it is necessary to make patients accept these pathologies, so that they can comply to the treatments [19]. Improving access to health care through universal health insurance, improvement of the medical technical platform and improving living standards are also essential.

\section{Conclusion}

Mortality for CVDs is represented by arterial hypertension and its complications, in addition to DCM. Preventive actions, and patient education seem necessary in this context. Similarly, co-morbidities (lower respiratory infections, anemia, and renal failure), need to be managed effectively.

\section{Conflicts of Interest}

None.

\section{References}

[1] Keates, A.K., Mocumbi, A.O., Ntsekhe, M., Sliwa, K. and Stewart, S. (2017) Cardiovascular Disease in Africa: Epidemiological Profile and Challenges. Nature Reviews Cardiology, 14, 273-293. https://doi.org/10.1038/nrcardio.2017.19

[2] Roth, G.A., Huffman, M., Moran, A.E., et al. (2015) Global and Regional Patterns in Cardiovascular Mortality from 1999 to 2013. Circulation, 135, 1667-1678. https://doi.org/10.1161/CIRCULATIONAHA.114.008720

[3] Gombet, T.R., Ellenga Mbolla, B.F., Ikama, M.S., Ekoba, J. and Kimbally-Kaky, G. (2009) Cost of Emergency Cardiovascular Care at the University Hospital Center in Brazzaville, Congo. Medecine Tropicale, 69, 45-47.

[4] Kingue, S., Ba, S.A., Balde, D., et al. (2016) The VALVAFRIC Study: A Registry of Rheumatic Heart Disease in Western and Central Africa. Archives of Cardiovascu- 
lar Disease, 109, 321-329. https://doi.org/10.1016/j.acvd.2015.12.004

[5] Kimbally Kaky, G., Gombet, T., Voumbo, Y., et al. (2008) Rheumatic Heart Disease in Schoolchildren in Brazzaville. Medecine Tropicale, 68, 603-605.

[6] Sliwa, K., Damasceno, A. and Mayosi, B.M. (2005) Epidemiology and Etiology of Cardiomyopathy in Africa. Circulation, 112, 3577-3583. https://doi.org/10.1161/CIRCULATIONAHA.105.542894

[7] Damasceno, A., Bongani, M., Sani, M., et al. (2012) The Causes, Treatment and Outcomes of Acute Heart Failure in 1006 Africans from 9 Countries. Results of the Sub-Saharan Africa Survey of Heart Failure. Archives of Internal Medicine, 172, 1386-1394. https://doi.org/10.1001/archinternmed.2012.3310

[8] Ellenga Mbolla, B.F., Ossou Nguiet, P.M., Ikama, M.S., et al. (2019) Rates of Untreated, Treated, and Controlled Hypertension and Relationship between Blood Pressure with Other Cardiovascular Risk Factors in Brazzaville (Republic of the Congo): May Measurement Month 2017, Sub-Saharan Africa. European Heart Journal Supplements, 21, D44-D46. https://doi.org/10.1093/eurheartj/suz085

[9] Piepoli, M.F., Hoes, A.W., Agewall, S., et al. (2016) 2016 European Guidelines on Cardiovascular Diseases Prevention in Clinical Practice. European Heart Journal, 37, 2315-2381. https://doi.org/10.1093/eurheartj/ehw106

[10] Sanyahumbi, A.S., Sable, C.A., Beaton, A., et al. (2016) School and Community Screening Shows Malawi, Africa, to Have a High Prevalence of Latent Rheumatic Heart Disease. Congenital Heart Disease, 11, 615-621. https://doi.org/10.1111/chd.12353

[11] Ikama, M.S., Moualengue, B., Makani, J., et al. (2018) Epidemioclinical and Evolutionary Profile of Dilated Cardiomyopathy at the University Hospital of Brazzaville, Congo. Pan African Medical Journal, 31, 164.

https://doi.org/10.11604/pamj.2018.31.164.16477

[12] Republic of the Congo (2017) Report on the Analysis of Poverty in Congo. Education, Employment and Social Protection for Sustainable Poverty Reduction. World Bank Group. http://documents.worldbank.org/curated/en/359991503510903731/pdf/114706-FRE NCH-v2-Republic-of-Congo-FRE-7-17-17-M3.pdf

[13] Eyeni Sinomono, T., Missamou, A.F.S., Gassongo Koumou, G.C. and Loumingou, R. (2018) Initiation de la dialyse à Brazzaville. Nephrologie et Therapeutique, 14, 307. https://doi.org/10.1016/j.nephro.2018.07.133

[14] Makubi, A. and Roberts, D.J. (2017) Investigation and Treatment for Iron Deficiency in Heart Failure: The Unmet Need in Lower and Middle-Income Countries. British Journal of Haematology, 117, 896-904. https://doi.org/10.1111/bjh.14650

[15] Amendezo, E., Twagirimukiza, M., Sebatunzi, O. and Kagame, A. (2008) Inhospital Cardiovascular Morbidity and Mortality in the Department of Internal Medicine at CHU Kigali (Rwanda). Annals of Tropical Medicine and Public Health, 1, 9-14. https://doi.org/10.4103/1755-6783.43071

[16] Amoah, A.G.B. and Kallen, C. (2000) Aetiology of Heart Failure as Seen from a National Cadiac Referral Centre in Africa. Cardiology, 93, 11-18. https://doi.org/10.1159/000006996

[17] Callender, T., Woodward, M., Roth, G., et al. (2014) Heart Failure Care in Low and Middle-Income Countries: A Systematic Review and Meta-Analysis. PLoS ONE, 11, e1001699. https://doi.org/10.1371/journal.pmed.1001699

[18] Bloomfield, G.S., Barasa, F.A., Doll, J.A. and Velazquez, E.J. (2013) Heart Failure in 
Sub-Saharan Africa. Current Cardiology Reviews, 9, 157-171. https://doi.org/10.2174/1573403X11309020008

[19] Cappucio, F.P. and Miller, M.A. (2016) Cardiovascular Disease and Hypertension in Sub-Saharan Africa: Burden, Risk and Interventions. Internal and Emergency Medicine, 11, 299-305. https://doi.org/10.1007/s11739-016-1423-9

[20] Ossou-Nguiet, P.M., Otiobanda, G.F., Ellenga Mbolla, B.F., Ikama, M.S., Ondze Kafata, L.I. and Bandzouzi, B. (2013) First Thrombolysis in Acute Stroke with Tenecteplase in Congo. International Journal of Stroke, 8, E47. https://doi.org/10.1111/ijs.12079

[21] Ikama, M.S., Makani, J., Jouven, X. and Kimbally Kaky, G. (2015) Permanent Cardiac Pacing: First Congolese Experiment. Pan African Medical Journal, 20, 381. https://doi.org/10.11604/pamj.2015.20.381.5803

[22] Alon, D., Stein, G.Y., Korenfeld, R. and Fuchs, S. (2013) Predictors and Outcomes of Infection-Related Hospital Admissions of Heart Failure Patients. PLOS ONE, 8, e72476. https://doi.org/10.1371/journal.pone.0072476 